\title{
Adsorption and Unfolding of a Single Protein Triggers Nanoparticle Aggregation
}

Sergio Dominguez-Medina, ${ }^{\dagger, \|, \#}$ Lydia Kisley, ${ }^{\dagger, \|, \Delta}$ Lawrence J. Tauzin, ${ }^{\dagger}$ Anneli Hoggard, ${ }^{\dagger}$ Bo Shuang, A. Swarnapali D. S. Indrasekara, ${ }^{\dagger}$ Sishan Chen, ${ }^{\dagger}$ Lin-Yung Wang, ${ }^{\dagger}$ Paul J. Derry, ${ }^{\dagger}$ Anton Liopo, ${ }^{\dagger}$ Eugene R. Zubarev, ${ }^{\dagger, \dagger}$ Christy F. Landes, ${ }^{*},, \S$ and Stephan Link ${ }^{*}, \dagger, \S$

${ }^{\dagger}$ Department of Chemistry, Rice University, Houston, Texas 77251, United States

${ }^{\ddagger}$ Department of Materials Science and NanoEngineering, Rice University, Houston, Texas 77251, United States

${ }^{\S}$ Department of Electrical and Computer Engineering, Rice University, Houston, Texas 77251, United States

\section{Supporting Information}

ABSTRACT: The response of living systems to nanoparticles is thought to depend on the protein corona, which forms shortly after exposure to physiological fluids and which is linked to a wide array of pathophysiologies. A mechanistic understanding of the dynamic interaction between proteins and nanoparticles and thus the biological fate of nanoparticles and associated proteins is, however, often missing mainly due to the inadequacies in current ensemble experimental approaches. Through the application of a variety of single molecule and single particle spectroscopic techniques in combination with ensemble level characterization tools, we identified different interaction pathways between gold nanorods and bovine serum albumin depending on the protein concentration. Overall, we found that local changes in protein concentration influence everything from cancer cell uptake to nanoparticle stability and even protein secondary structure. We envision that our findings and methods will lead to strategies to control the associated pathophysiology of nanoparticle exposure in vivo.

KEYWORDS: protein corona, nanorods, superlocalization microscopy, correlation spectroscopy, surface plasmon

$\mathrm{T}$ he interaction of nanoparticles with living organisms has received growing attention in the past decade ${ }^{1-3}$ due to the development of novel therapeutic and diagnostic tools, ${ }^{4-6}$ and the growing concerns regarding the safety of nanomaterials in vivo. ${ }^{7-11}$ It is understood that nanoparticles adsorb proteins in biological fluids forming a "protein corona", which influences the nanoparticle physicochemical properties and subsequent interactions with the physiological environment. ${ }^{12-27}$ Both the possibility that in vivo administration of therapeutic nanoparticles can disturb the structural integrity of proteins and the current knowledge of the direct link between denatured proteins and severe neurodegenerative diseases suggest that nanotherapeutic platforms potentially pose a health risk..$^{2,28-30}$ Therefore, understanding the interaction of proteins with nanoparticles on a molecular level is paramount for the efficient and safe application of engineered nanoparticles.

The quantification and identification of the protein corona composition for different types of nanoparticles with varying surface chemistries have been undertaken. ${ }^{12,14,30-34}$ Ex situ ensemble techniques such as gel electrophoresis coupled with mass spectrometry have been widely used to characterize the chemical identity and abundance of constituent corona proteins after separation from the nanoparticles. ${ }^{12,29}$ Less disruptive, complementary optical spectroscopy approaches can be used to study the protein-nanoparticle complex in situ and were able to determine the thermodynamics of protein binding as well as to provide insight into the interactions between protein coated nanoparticles and cells. ${ }^{15,35-38}$ For instance, the micromolar affinity of serum albumin to colloidal nanoparticles resulting in a protein monolayer ${ }^{15}$ at physiological concentrations and enhanced colloidal stability in plasma ${ }^{39}$ have been revealed by a combination of UV-vis and fluorescence correlation spectroscopic techniques. Payne and co-workers have used superresolution optical imaging under in vitro conditions, and demonstrated that what cellular receptors actually screen are the adsorbed proteins and not the initially synthesized nanoparticles themselves. ${ }^{40,41}$ Spectroscopic methods are ideally suited to characterize changes in protein structure

Received: October 13, 2015

Accepted: January 11, 2016

Published: January 11, 2016 

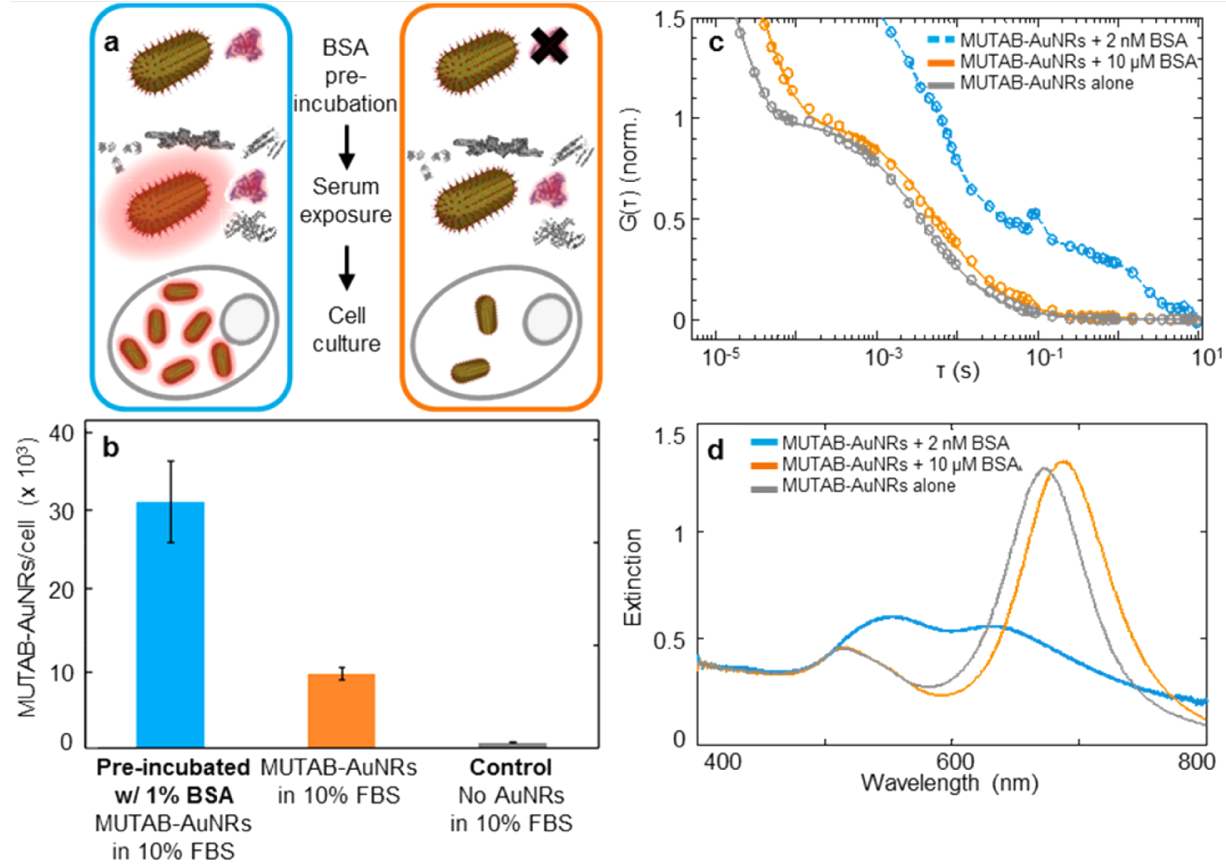

Figure 1. Preincubation of MUTAB-AuNRs with low concentrations of BSA strongly influences AuNR cell uptake, BSA protein adsorption, and NR aggregation. (a) Cartoon representation of (left, blue) preincubation of MUTAB-AuNRs with low concentration of BSA compared to (right, orange) MUTAB-AuNRs exposed to high concentration of proteins in serum without preincubation. (b) Number of MUTAB-AuNRs uptaken per MCF-7 cell for MUTAB-AuNRs preincubated with 1\% BSA before suspending in 10\% FBS and Eagle's minimum essential medium (EMEM), compared to MUTAB-AuNRs only suspended in 10\% FBS and EMEM. Cells suspended in 10\% FBS and EMEM without MUTAB-AuNRs are shown as a control. (c) Increases in MUTAB-AuNR fluctuation correlation decay time caused by BSA adsorption. Luminescence correlation decays for MUTAB-AuNRs alone (gray), incubated with low concentrations of BSA (blue) vs in higher serum-level BSA concentrations (orange). Autocorrelation curves with respective decay fits shown as solid lines. Under low BSA concentration, the fit did not follow a predictable model; dashed line is instead shown as a guide for the eye. (d) UV/vis spectra under similar conditions as (c) suggest MUTAB-NR aggregation occurs when incubated at low concentrations of BSA.

when bound to a nanoparticle surface. The structural integrity of the corona proteins, which domains of the protein bind and which ones potentially change their structure, ${ }^{28,42-48}$ has been studied by using far- and near-UV circular dichroism (CD), ${ }^{28,42,43,49,50} \mathrm{IR}^{43,50}$ and Raman ${ }^{44}$ spectroscopy.

While the protein-nanoparticle community has begun to transition from the mere identification of adsorbed proteins to the understanding of the physiological responses that can arise due to the presence of the protein corona, it is still not fully understood how protein adsorption affinities, relative concentrations, and surface chemistries are ultimately linked to the corona composition and to possible structural changes of the proteins. A mechanistic bridge between these aspects is lacking due to the low spatiotemporal resolution and ex situ requirements of most current techniques. ${ }^{18}$ Ensemble analytical techniques that assume quasi-equilibrium conditions with exchange between free and bound proteins have furthermore led to controversial results. ${ }^{12,19,30-33,51}$

Here, we have used a combined approach of ensemble and single protein/single nanoparticle methods to answer the following questions about the nanoparticle protein corona: Is thermodynamic equilibrium a valid concept for the protein corona as local changes in protein concentrations occur? How does protein adsorption influence protein chemistry? How is nanoparticle stability altered? Finally, how might equilibrium and nonequilibrium protein/nanoparticle interactions influence physiological outcomes? Mechanistic understanding of the physicochemical properties of bovine serum albumin (BSA) adsorbed to cationic-ligand functionalized gold nanorods
(AuNRs) is studied here as the experimental system. While an ensemble protein adsorption isotherm implicates the adsorption of several proteins to the nanoparticle surface, single protein/single nanoparticle interactions visualized through superlocalization imaging reveal that in fact only one protein is irreversibly adsorbed at a time. The seemingly conflicting findings are resolved through surface plasmon coupled CD spectroscopy, and demonstrate that the local changes in protein concentration affect the colloidal stability of nanoparticles, protein secondary structure and eventually cellular uptake of nanoparticles.

\section{RESULTS AND DISCUSSION}

When nanoparticles are preincubated in BSA at lower than physiological concentrations, properties such as uptake by MCF-7 cancer cells, BSA adsorption, and nanoparticle aggregation are strongly influenced (Figure 1). Cationic mercaptoundecyltrimethylammonium bromide coated AuNRs (MUTAB-AuNRs) incubated in $10 \%$ fetal bovine serum (FBS) are uptaken by MCF-7 cancer cells (Figure 1a,b). ${ }^{52}$ However, with preincubation of the MUTAB-AuNRs in $1 \%(\mathrm{w} / \mathrm{v}) \mathrm{BSA}$, the uptake is increased 3 -fold (Figure $1 \mathrm{~b}$ ). This increase is not due to MUTAB-AuNRs adhered to the outside of the cells as the cells are washed several times with PBS following a previously published protocol. ${ }^{52}$ As the most abundant serum protein, BSA is present in higher concentrations in FBS than $1 \%(\mathrm{w} / \mathrm{v})$. Preincubation of MUTAB-AuNRs with $1 \%(\mathrm{w} / \mathrm{v})$ $\mathrm{BSA}$, however, seems to influence their interaction with cancer cells and causes increased uptake. It is thus important to 

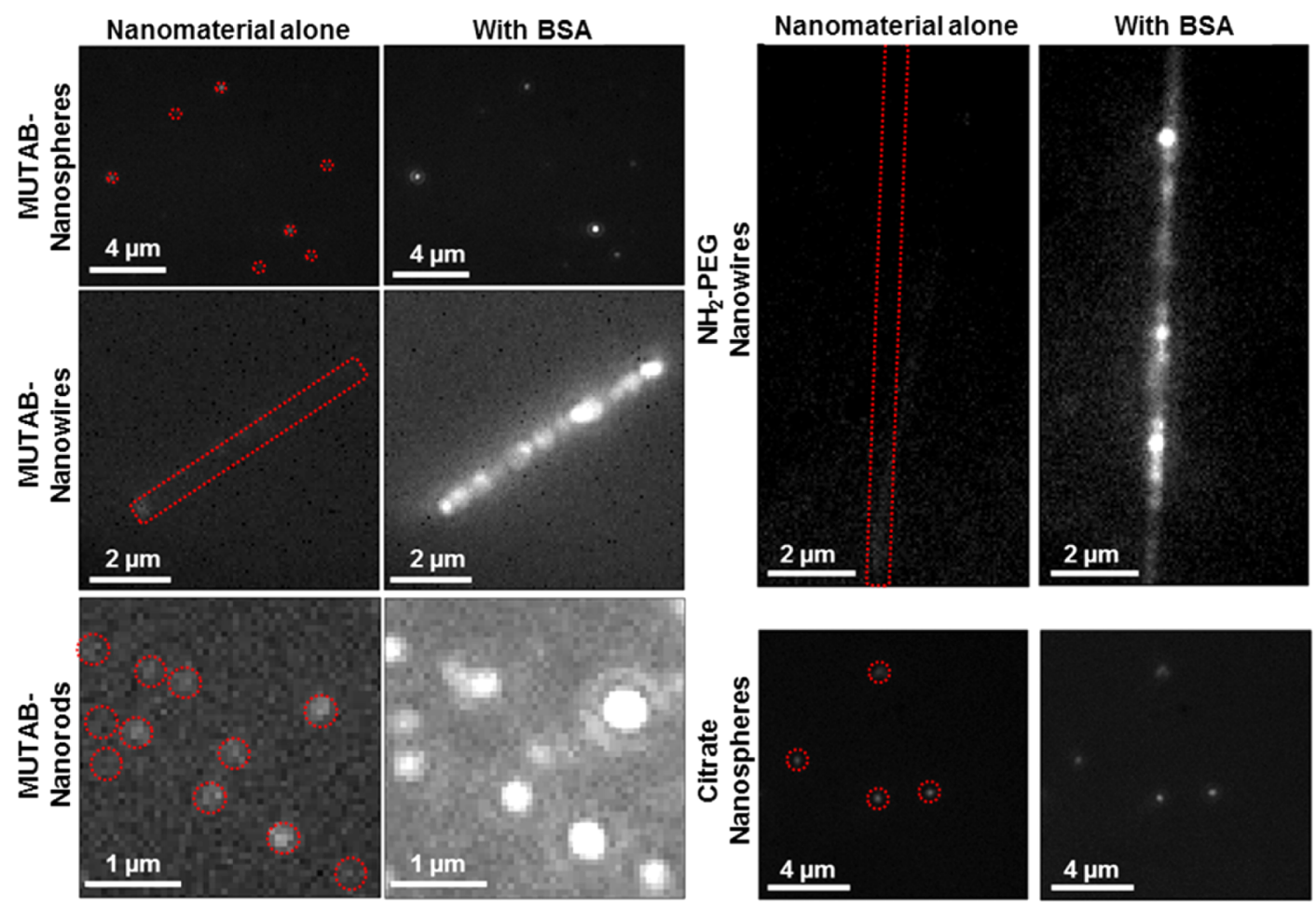

Figure 2. Single molecule imaging of BSA interactions with nanomaterials of varying geometries (sphere, wire, rod) and surface chemistries (cationic MUTAB, cationic $\mathrm{NH}_{2}$-PEG-SH, anionic citrate). Images show nanomaterial highlighted with dashed red outline (left) before and (right) after $2 \mathrm{nM}$ Alexa-BSA is introduced. Images are binned, ranging from 10 to 100 frames. These results show that BSA binding occurs independent of the nanoparticle geometry. Furthermore, a different surface chemistry also facilitates binding as long as the surface charge remains positive. No significant adsorption is seen for negative charged citrate capped nanoparticles at this BSA concentration.

understand if and how the BSA-based protein corona is protein dependent. In situ ensemble, single molecule, and single particle spectroscopies are used to address these issues.

Luminescence correlation spectroscopy provides strong support that the BSA protein corona that forms on MUTABAuNRs is concentration dependent (Figure 1c). At high protein concentrations $(20 \mu \mathrm{M})$, the increase in measured hydrodynamic radius matches the dimensions of native $\mathrm{BSA}^{53}$ and hence implies the formation of a protein monolayer, consistent with earlier reports of BSA monolayer formation on nanoparticles (Table S1). ${ }^{15,54,55}$ In contrast, at lower BSA concentrations $(2 \mathrm{nM})$, the luminescence correlation decay shifts to longer average decay times, indicating that surprisingly the nanoparticle-protein complex has become even larger than what is observed under the high BSA concentration conditions. Most importantly, the data could not be fit to an equilibrium adsorption model, suggesting nonequilibrium behavior, consistent with nanoparticle aggregation as verified further below.

Further support for the strong deviation between low and high BSA concentrations is found in the UV-vis spectra (Figure 1d). At high BSA concentrations, the extinction spectrum of the MUTAB-AuNRs is slightly red-shifted, due to a change in dielectric environment and consistent with equilibrium formation of a stable BSA monolayer. However, at low BSA concentrations, the decreased intensity and resonance shift of the plasmon resonance indicate that the MUTABAuNRs aggregate in the presence of low BSA concentrations.

The combination of our results on cancer cell uptake, protein adsorption, and nanoparticle colloidal stability strongly suggest that local protein concentrations must be considered when assessing corona chemistry and its influence on nanoparticles' ultimate physiological fate, as suggested previously. ${ }^{11,20}$ Of particular interest in Figure 1 is the case of low protein concentrations. Low protein-to-nanoparticle ratios can, for example, occur under controlled preincubation conditions after injection into a living organism and upon accumulation in cellular compartments. Thus, we examine more closely the structure of BSA and nanoparticles when they interact at low concentrations and suggest how these processes lead to the ultimate fate of the protein-nanoparticle colloid.

BSA adsorbs at low concentrations to cationic ligand-coated gold nanomaterials of varying geometries (Figure 2). A $2 \mathrm{nM}$ concentration of Alexa647-labeled BSA (3 dyes per protein) is flowed over individual nanomaterials of varying surface chemistries (cationic MUTAB, cationic amine poly(ethylene glycol) $\left[\mathrm{NH}_{2}-\mathrm{PEG}\right]$, and anionic citrate) and different geometries (nanospheres $[\sim 50 \mathrm{~nm}$ diameter $]$, nanowires [width, $\sim 70 \mathrm{~nm}$; length, $1-10 \mu \mathrm{m}$ ], and nanorods [width, 20 $\mathrm{nm}$; length, $58 \mathrm{~nm}]$ ). BSA binding to these different nanostructures is visualized via an increase in fluorescence intensity due to adsorption of the fluorescently labeled protein. Because of total internal refection excitation, only individual molecules at the surface are registered, while freely diffusing proteins contribute to a slightly larger average background signal. $^{56} \mathrm{We}$ find that BSA binds to the cationic-ligand functionalized nanomaterials at this low concentration. On the other hand, negligible binding of BSA to the citrate capped nanospheres is observed under the same conditions. Much higher micromolar concentrations are needed for this ligand. ${ }^{35}$ To understand the mechanistic details of protein adsorption at low concentrations to cationic nanomaterials, we will concentrate on the interactions between MUTAB-AuNRS 
and BSA as example nanoparticle supports and serum proteins, respectively.

Single molecule analysis of the fluorescence imaging data reveals that only one BSA protein binds irreversibly to each MUTAB-AuNR (Figure 3). BSA adsorption onto single
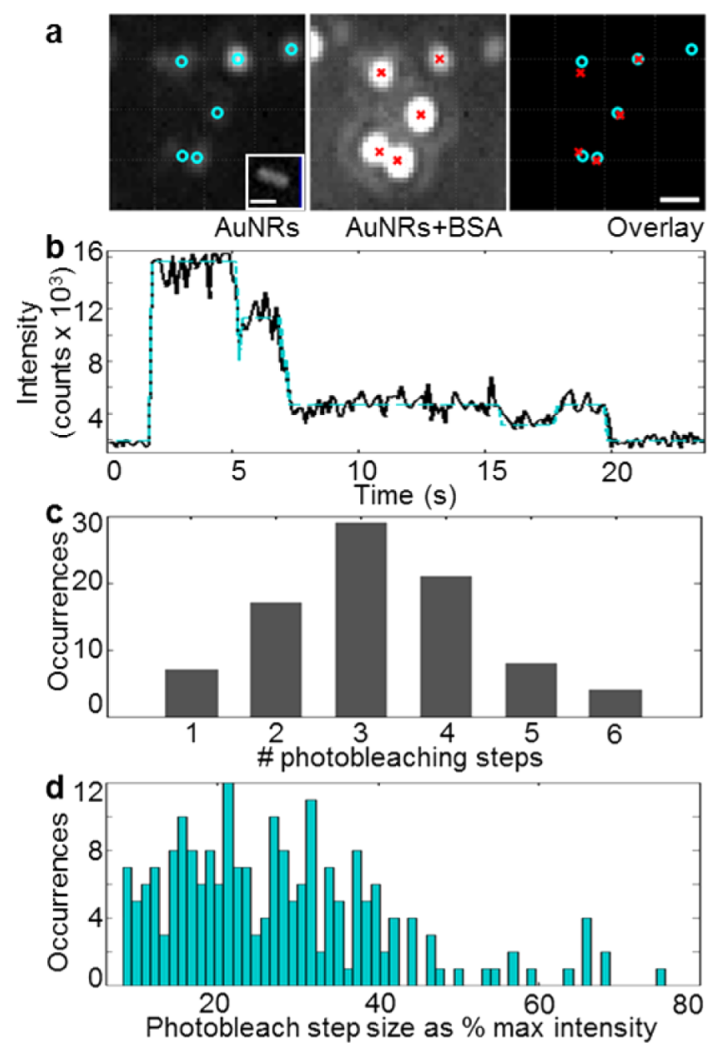

Figure 3. Single BSA proteins adsorb to single MUTAB-AuNRs. (a) Colocalization of single MUTAB-AuNRs, confirmed by SEM (inset; scale bar, $50 \mathrm{~nm}$ ), with fluorescently labeled BSA. Fluorescence images are $\mathbf{7 4}$ frames binned with the same intensity; scale bar $\mathbf{5 0 0}$ $\mathrm{nm}$. AuNRs are visible through their weak intrinsic photoluminescence using long exposure times before introducing BSA. (b) Intensity transient (black) of BSA adsorbed to a MUTABAuNR with state and step identification (teal dashed line) of photobleaching steps. (c) Distribution of the number of photobleaching steps for 86 transients. (d) Simultaneous photobleaching steps are unlikely. For a labeling density of 3 fluorophores per BSA molecule, the average photobleaching step size as a percent of the maximum intensity should be $\sim 33 \%$, which is indeed confirmed by the observed average step size of $30 \pm 10 \%$. A value of $>66 \%$ indicates simultaneous photobleaching events. Out of the 213 photobleaching steps analyzed, $<4 \%$ of steps had values greater than $60 \%$.

MUTAB-AuNRs is identified by colocalization ${ }^{57}$ of dye fluorescence and intrinsic AuNR luminescence (Figure 3a, Figures S1-S3 and Video S1). Scanning electron microscopy (SEM) image analysis confirms that $99 \%$ of the analyzed BSA adsorption events occur at single MUTAB-AuNRs (Figure S4) with little nonspecific BSA interaction with the substrate because of surface passivation (Figure S5).

Although BSA in its native form is smaller than a AuNR, we find no evidence for multiple BSA adsorption by analyzing fluorescence time transients (Figure $3 b, c$ ). Protein adsorption is observed as an increase in fluorescence intensity, followed by a stepwise decrease as each of the dye molecules on the protein photobleaches (Figure 3b). Photobleaching step and intensity distribution analyses are commonly used in single molecule experiments to detect single $v s$ oligomer states of proteins, ${ }^{58,59}$ including proteins with multiple dyes. ${ }^{60,61}$ The number of photobleaching steps identified by an established step-finding algorithm ${ }^{46}$ is thus a direct measure of the BSA molecules per AuNR (Figure 3b, line). Analysis for 86 AuNRs yields an average of $3.2 \pm 1.2$ photobleaching steps (Figure 3c), matching the single protein labeling density indicated by the supplier (Molecular Probes, A34785). Further controls involve eliminating the presence of simultaneous photobleaching of multiple dyes (Figure 3d), reversible protein desorption/ readsorption (Figure S6), or dye fluorescence quenching close to the AuNRs (Video S2). In particular, Figure 3d confirms that despite the labeling with 3 dyes a BSA molecule does not behave as a multichromophoric system capable of simultaneous off/on blinking of all dyes due to energy transfer.

The adsorption of single BSA proteins to single MUTABAuNRs is irreversible on a time scale of $8 \mathrm{~h}$ as demonstrated by a constant percentage of AuNR-BSA complexes while continuously rinsing with buffer solution without proteins (Figure 4). It is not clear, however, if this observation of only a

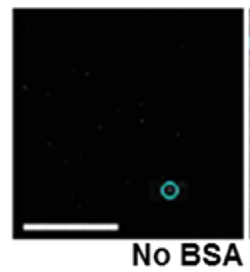

b

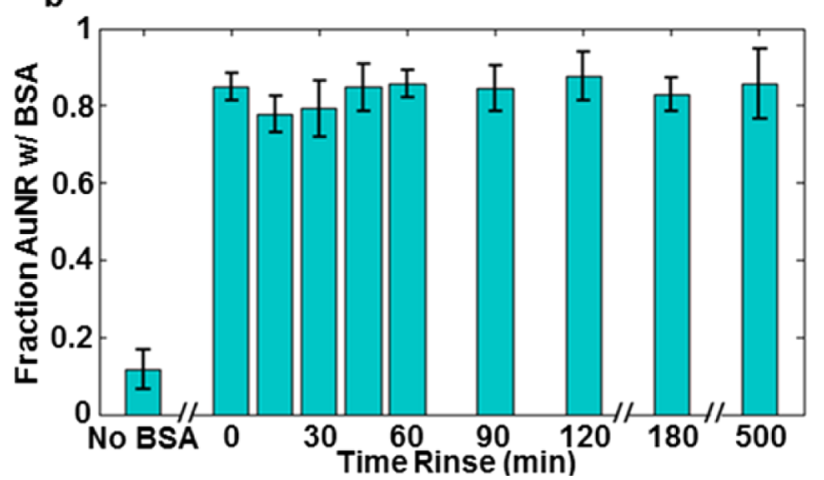

Figure 4. Irreversible adsorption of BSA to MUTAB-AuNRs. (a) Representative images of BSA/MUTAB-AuNRs identified based on the stronger BSA signal (circles) before (No BSA), after $(t=0 \mathrm{~min})$ adding a $2 \mathrm{nM}$ BSA solution, and after $500 \mathrm{~min}$ of rinsing with buffer. False identification (No BSA) is likely due to $<1 \%$ of AuNR aggregates with higher photoluminescence intensities. Scale bar, 5 $\mu \mathrm{m}$. (b) Percent of MUTAB-AuNRs with adsorbed BSA molecules identified before and after rinsing. Values calculated from five different, uncorrelated $400 \mu \mathrm{m}^{2}$ areas for each data point to avoid photobleaching.

one protein adsorbing to each immobilized MUTAB-AuNR extends to the solution case. The exposed AuNR surface area is about twice as large in solution, but the protein-to-nanoparticle ratio is only $\sim 26$, as $\sim 75 \mathrm{pM}$ nanorods are exposed to $2 \mathrm{nM}$ BSA. It is not trivial to quantify this ratio for MUTAB-AuNRs immobilized on a substrate, but we estimate this number to be orders of magnitude larger given that $2 \mathrm{nM}$ BSA $\left(\sim 10^{8}\right.$ BSA proteins $/ \mu \mathrm{L}$ ) is flowed over single nanorods spaced out at least 
$1 \mu \mathrm{m}$ from each other at a flow rate of $5 \mu \mathrm{L} / \mathrm{min}$ for $15 \mathrm{~min}$. Regardless of the experimental geometry (i.e., free MUTABAuNRs in solution vs immobilized on a surface), there is space for many dozens of proteins to bind to each AuNR (width $=20$ $\mathrm{nm}$, length $=58 \mathrm{~nm}$; resulting surface area of $\left.\sim 3000 \mathrm{~nm}^{2}\right)$, assuming a native BSA conformation that can be approximated by an equilateral triangular prism with 2 triangular facets of $\sim 28$ $\mathrm{nm}^{2}$ and 3 smaller rectangular sides of $\sim 12 \mathrm{~nm}^{2}$. ${ }^{53}$ The only hypothesis that explains how the strong, irreversible adsorption of single (or few) BSA molecules can lead to the results shown in Figure 1 is if BSA is undergoing structural changes upon adsorption.

Using CD spectroscopy and subdiffraction localization microscopy, we find that BSA undergoes an unprecedented large loss in $\alpha$-helical structure when adsorbed to MUTABAuNRs (Figure 5). BSA is primarily $\alpha$-helical in secondary

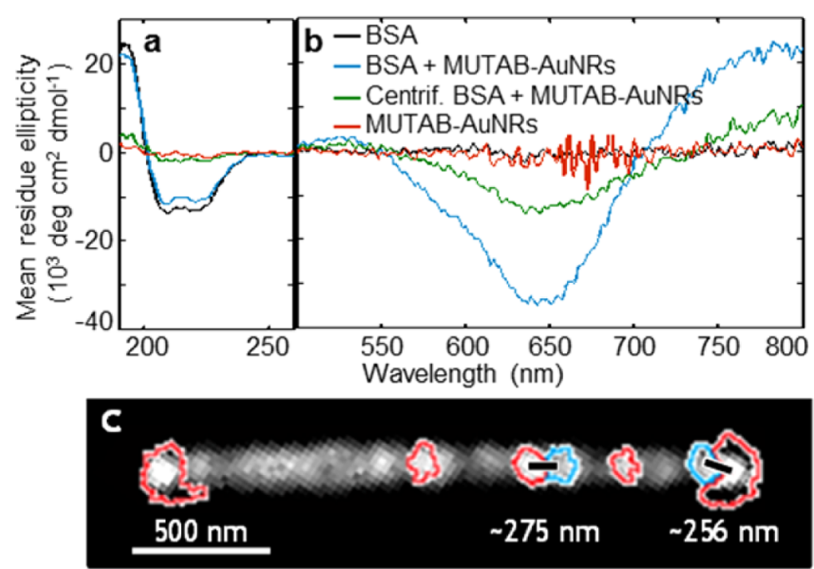

Figure 5. Unfolding of BSA upon adsorption to MUTAB-AuNRs. (a) UV and (b) surface plasmon coupled CD spectra of $1 \mathrm{mg} / \mathrm{mL}$ of BSA alone (black), BSA/MUTAB-AuNRs (blue), centrifuged BSA/ MUTAB-AuNRs (green), and MUTAB-AuNRs alone (red). Magnified view of UV region provided in Figure S12c. (c) Superresolution map of identified individual BSA molecules, represented by different colored outlines, based on cross-correlation analysis. The identified BSA locations are overlaid on the average fluorescence image. Representative distances between neighboring BSA molecules are shown. See Figures S13 and S14 for further details regarding data analysis.

structure. Therefore, increases in the negative peaks at 209 and $222 \mathrm{~nm}$ and decreases in the positive peak at $192 \mathrm{~nm}$ in the UV CD spectrum indicate a loss of BSA $\alpha$-helical structure in the presence of MUTAB-AuNRs (Figure 5a). Similar behavior is observed for MUTAB-coated Au nanospheres (Figures S7 and $\mathrm{S} 8$ ), in contrast to citrate-capped Au nanospheres or in the presence of only MUTAB ligand (Figures S9, S10a, S11). From the UV CD signal, we calculate the loss of protein order using the DichroWeb K2d neural network secondary structure analysis $^{62,63}$ to be $20 \pm 9 \%$, similar to results obtained on cationic-functionalized silica particles. ${ }^{49}$ This analysis, however, provides only a low estimate because of unbound native BSA in solution. After centrifugation and removal of the supernatant solution, the CD signal is much weaker, while the supernatant solution shows a comparable $\mathrm{CD}$ signal to the uncentrifuged sample (Figure 5a, Figure S10b).

For another estimation of the loss of $\alpha$-helical structure and to ensure that BSA remains adsorbed to the MUTAB-AuNRs after centrifugation, we turn to surface plasmon coupled $C D$ spectroscopy in the visible spectral region (Figure 5b). A strong $\mathrm{CD}$ signal in the visible region at the plasmon resonance is observed due to the chiral BSA protein adsorbed onto the nonchiral MUTAB-AuNRs. Plasmonic nanomaterials can act as strong visible light antennas for the chirality of surface adsorbed molecules, manifested by a chiral response of the plasmon resonance itself. ${ }^{64-67}$ After centrifugation, the surface plasmon coupled CD signal is still observed, confirming the presence of BSA (Figure $5 \mathrm{~b}$ ). The decrease in CD intensity quantitatively matches the decrease in the optical density and is therefore due to the loss of AuNRs during centrifugation (Figure S10c). This data allows us to calculate an upper limit of $\sim 70 \%$ change in $\alpha$ helical structure of BSA adsorbed to MUTAB-AuNRs (Figures S8 and S10):

$$
\begin{aligned}
1 & -\frac{\mathrm{CD}_{209, \text { centrif.BSA+MUTAB- AuNRs }}}{\mathrm{CD}_{209, \mathrm{BSA}}} \times \frac{\mathrm{CD}_{645, \mathrm{BSA}+\mathrm{MUTAB}-\mathrm{AuNRs}}}{\mathrm{CD}_{645, \text { centrif. BSA+MUTAB- AUNRs }}} \\
& =1-\frac{1.66}{13.57} \times \frac{34.78}{14.05}=0.69
\end{aligned}
$$

where these values are extracted from the CD spectra measured in $\mathrm{mDeg}$ in the UV $(209 \mathrm{~nm})$ and visible regions $(645 \mathrm{~nm})$ shown in Figure 5a,b. The correction factor ( $\mathrm{CD}_{645, \text { BSA+MUTAB-AuNRs }} / \mathrm{CD}_{645 \text {,centrif.BSA+MUTAB-AUNRs }}$ ) is used to take into the account the loss of BSA bound MUTAB-AuNRs in the centrifugation step, making use of the plasmon-coupled CD signal.

Subdiffraction localization mapping of protein binding to nanowires supports the large extent of unfolding (Figure 5c). Larger Au nanowires functionalized with MUTAB (width, 70 $\mathrm{nm}$; length, $1-10 \mu \mathrm{m}$ ) are exposed to $1 \mathrm{nM}$ BSA and multiple protein binding events are imaged. Most of the available nanowire surface area is covered by BSA (Figure 2). Because of this high coverage, the smallest distance between nearestneighbor proteins is determined by cross-correlating the intensity transients of neighboring pixels (Figures S13 and S14). Such analysis, compared to superlocalization mapping of individual fluorophores, ${ }^{56,68}$ is less affected by possible distortions in the point spread functions of the protein dye labels due to their positions and orientations ${ }^{69}$ on a plasmonic substrate. Figure $5 \mathrm{c}$ shows the most likely locations of seven individual BSA proteins adsorbed onto a large MUTAB-Au nanowire identified with high confidence. The average distance between neighboring unfolded BSA proteins is larger than 200 $\mathrm{nm}$ and explains why only a single BSA molecule can bind to the available surface area of the smaller MUTAB-AuNRs. On the basis of the change in adsorbed protein structure, it is possible to explain the nanoparticle aggregation at low BSA concentrations (Figure 1d).

An unfolded BSA corona on MUTAB-AuNRs causes AuNR aggregation (Figure 6). MUTAB-AuNRs preincubated with BSA form aggregates with immobilized MUTAB-AuNRs that were similarly preincubated with BSA. Figure 6a shows a cartoon of the experiment conditions, in which large aggregates are formed on the substrate as observed by SEM (Figure 6b, insets). Particle size analysis quantifies a large increase in both the number of structures (single AuNRs and aggregates) and distribution of surface areas for the samples with substrate and solution BSA/MUTAB-AuNR in comparison to samples consisting of only one of the components (Figure S15 and Table S2).

Consistent with irreversible BSA binding, we find no evidence for protein aggregates in solution (Figure S11). 


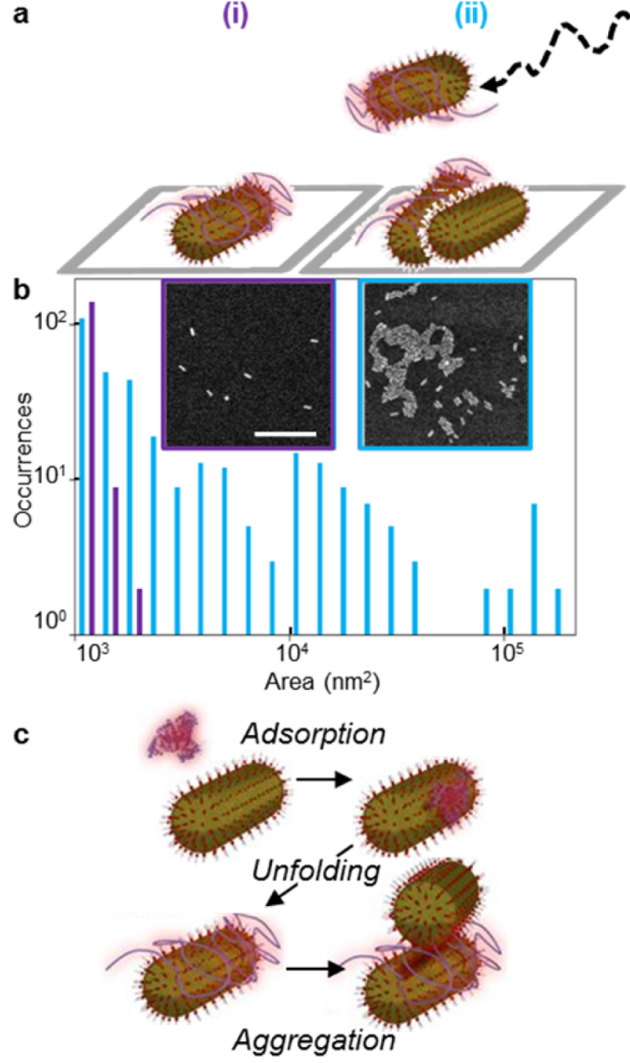

Figure 6. Nanoparticle aggregation is induced by interactions between unfolded proteins. (a) Cartoon showing a MUTAB-AuNR immobilized on a substrate (i) and aggregation of such supported AuNR with BSA coated AuNRs in solution when 2 nM BSA/ MUTAB-AuNRs is introduced into the flow cell (ii). Samples were imaged by SEM (insets, scale bar, $500 \mathrm{~nm}$ ). (b) The $\log -\log$ scale distribution quantifies the AuNR particle surface areas observed within $235 \mu \mathrm{m}^{2}$ of the SEM images. Both single AuNRs and isolated aggregates were counted as individual particles. Case (ii) shows a large increase in the number of particles $n$ and the distribution of surface areas $A$ (blue, $\left.n=333 ; A=(17000 \pm 50000) \mathrm{nm}^{2}\right)$, while for case (i), exclusively single particles are found (purple, $n=152$; $\left.A=(1300 \pm 200) \mathrm{nm}^{2}\right)$. Further controls and analysis are provided in the Supporting Information (Figure S15, Table S1). (c) Proposed model in which single protein adsorption and unfolding induce aggregation.

Further, anionic citrate-capped $\mathrm{Au}$ nanospheres, which adsorb BSA but do not induce unfolding, do not aggregate (Figure S9). Most interestingly, fibrinogen and globulin cause aggregation of MUTAB-AuNRs not only at low protein concentration, but also at physiological conditions, potentially making the behavior of BSA unique among the most abundant serum proteins (Figure S16). We therefore hypothesize that protein unfolding on a highly charged nanoparticle surface is in general a favorable process, but at the high physiological concentrations of BSA, its designed biological function as a solubilizing and transporting agent dominates due to complete monolayer coverage. This aspect will be subject of future work. It should be mentioned that, while this work was under review, a similar counterintuitive relationship between protein concentration and nanoparticle aggregation was published by Cedervall and co-workers. ${ }^{70}$ Despite using negatively charged polystyrene nanoparticles suspended in cow serum, they found that IgG can induce nanoparticle aggregation at low protein concentrations, while at high concentrations, a protein monolayer prevents the formation of large nanoparticle aggregates.

\section{CONCLUSIONS}

On the basis of our experimental results obtained from a variety of single molecule/particle and ensemble techniques, we propose a nonequilibrium mechanism in which irreversible protein adsorption occurs at low protein-to-nanoparticle ratios and is followed by BSA unfolding (Figure 6c). In turn, unfolded BSA-BSA interactions drive the nanoparticle aggregation process. Although protein-induced nanoparticle aggregation $^{28,43}$ has been reported in the literature, we believe we have provided a mechanistic explanation of how this process can happen under specific conditions. Furthermore, we have directly addressed the questions posed above. First, although we often model protein adsorption as a dynamic equilibrium, it is clear that under certain circumstances, the interaction between serum proteins and nanoparticles can undergo strong nonequilibrium processes such as unfolding and aggregation. Our results more broadly imply that modeling of protein adsorption on nanoparticles using commonly employed equilibrium binding constants may describe at best a pseudoequilibrium occurring at large protein to nanoparticle ratios. Next, the extreme changes detected in MUTAB-AuNR size in the presence of low concentrations of BSA are consistent with unfolding of single (or few) proteins on single AuNRs followed by aggregation driven by unfolded BSA-BSA interactions. As for the last and most difficult question, we present strong support of a hypothesis in which the interaction of MUTAB-AuNRs or other therapeutic nanoparticles with even small amounts of plasma proteins, along with their subsequent change in secondary structure, could strongly influence their ultimate fate, be that for good or bad. Much further work is required to test this hypothesis. Regardless, these results show how the protein-to-nanoparticle ratio influences the physical chemistry of the protein corona, and that achieving a single protein level of mechanistic insight will deepen our understanding of the connections between protein corona composition, structure and in vivo physiological pathways.

\section{MATERIALS AND METHODS}

Gold Nanoparticles. Commercially available AuNRs (A12-25750, Nanopartz, Loveland, CO, USA) suspended in water and coated with cetyltrimethylammounium bromide $(\mathrm{CTAB})$ were functionalized with MUTAB, a cationic ligand that covalently attaches to the gold surface via a sulfur bond. Excess $\mathrm{CTAB}$ was removed by centrifugation of the stock solution for $10 \mathrm{~min}$ at $7500 \mathrm{rpm}$. The AuNRs were then resuspended in $1 \mathrm{mg} / \mathrm{mL}$ MUTAB in Millipore $\mathrm{H}_{2} \mathrm{O}(>1 \mathrm{M} \Omega)$ and placed overnight in a water bath at $35{ }^{\circ} \mathrm{C}$. Excess MUTAB was removed by centrifugation at $7500 \mathrm{rpm}$ for $10 \mathrm{~min}$ and replaced with Millipore $\mathrm{H}_{2} \mathrm{O}$ for storage. We estimate that the final concentration of free MUTAB in solution after this centrifugation step was less than $0.01 \mathrm{mg} / \mathrm{mL}$. The MUTAB-AuNR solutions were positively charged $(\zeta=35 \pm 5 \mathrm{mV})$ at $\mathrm{pH} 7.2$ according to zeta-potential measurements (Malvern Zen 3600). Further analyses of the MUTAB-AuNRs in the buffer conditions of the experiments $(20 \mathrm{mM}$ HEPES, $20 \mathrm{mM} \mathrm{NaCl}$ in Molecular Biology Grade $\mathrm{H}_{2} \mathrm{O}$ ) by UV/vis spectroscopy (Figures $\mathrm{S} 17$ and S18) and by transmission electron microscopy (TEM) (Figure S19) are included in the Supporting Information.

Commercially available citrate-coated gold nanospheres (AuNPs) with a nominal diameter of $50 \mathrm{~nm}$ were purchased from BBI solutions (Cardiff, U.K.). Sizing performed by the manufacturer using TEM showed that their actual size is $48 \pm 4 \mathrm{~nm}$ (Batch \# 16659, $75 \mathrm{pM}$ concentration based on the mass of gold per milliliter used for the 
synthesis). For the control experiments shown in Figures S7-S9, citrate-AuNPs were functionalized with MUTAB using the same procedure as described above for the AuNRs. The zeta-potential of the AuNPs went from negatively charged $(\zeta=-35 \pm 5 \mathrm{mV})$ in the presence of citrate, to positively charged once functionalized with $\operatorname{MUTAB}(\zeta=40 \pm 5 \mathrm{mV})$, confirming the ligand exchange reaction occurred.

Gold nanowires (Au nanowires, diameter $\sim 70 \mathrm{~nm}$, length 1-10 $\mu \mathrm{m})$ were synthesized using a modified three-step seeding synthesis originally developed for AuNRs. ${ }^{71}$ Seed particles were prepared by a rapid reduction of $\mathrm{HAuCl}_{4}$ (gold precursor) using $\mathrm{NaBH}_{4}$ (reducing agent). These particles were then grown in a solution containing $\mathrm{HAuCl}_{4}$, ascorbic acid, and CTAB. The presence of ascorbic acid reduces the gold salt from its $\mathrm{Au}(\mathrm{III})$ to a stable $\mathrm{Au}(\mathrm{I})$ state. Further addition of seeds to this solution induces an autocatalytic reaction of $\mathrm{Au}(\mathrm{I})$ that enlarges the seed particles. While this method would typically yield nanowires with an aspect ratio smaller than 10 , aspect ratios larger than 100 can be achieved when the reaction takes place in an acidic environment $(\mathrm{pH} \sim 2)$ and less seeds are added to the growth solution. $\mathrm{CTAB}$ on the as-synthesized $\mathrm{Au}$ nanowires was replaced with MUTAB. The CTAB-Au nanowires sedimented at the bottom of the vial after $1-2 \mathrm{~h}$ at room temperature without mixing or shaking. Carefully, CTAB was removed out of solution without removing the nanowires. An equal volume of MUTAB $(1 \mathrm{mg} / \mathrm{mL}$ in Millipore $\mathrm{H}_{2} \mathrm{O}$ ) was added to fill the volume left by removed CTAB. The solution was mixed using a micropipette and placed overnight in a water bath at $35{ }^{\circ} \mathrm{C}$. The MUTAB-Au nanowires were then resuspended in solution by gently shaking the vial, and then left untouched for $1-2 \mathrm{~h}$ at room temperature to allow sedimentation. Finally, excess MUTAB was removed out of solution (carefully without removing the nanowires), and an equal volume of Millipore $\mathrm{H}_{2} \mathrm{O}$ was added to fill the volume left by excess MUTAB.

Cell Culture. BSA (7.5\% in DBPS), penicillin-streptomycin (10000 U-10 mg/mL), $\mathrm{HCl}$ (Trace Metals Grade) and $\mathrm{HNO}_{3}$ (Trace Metals Grade) were purchased from Sigma-Aldrich. MCF-7 cells were acquired from ATCC (HTB-22). EMEM (with EBSS and LGlutamine) was purchased from Lonza. FBS (heat-inactivated) was purchased from Seradigm. Lactate dehydrogenase (LDH) activity assay kit was purchased from Thermo Scientific. All chemicals were used without further purification.

Microscope Glass Coverslips. Glass coverslips $\left(22 \times 22 \mathrm{~mm}^{2}\right.$, VWR) were cleaned by sonication for $10 \mathrm{~min}$ in acetone, $10 \mathrm{~min}$ in water/detergent mixture, and $10 \mathrm{~min}$ in deionized water. The coverslips were then immersed in a bath of base (6:1:1 water, 30\% $\mathrm{H}_{2} \mathrm{O}_{2}, \mathrm{NH}_{4} \mathrm{OH}$ ) for $90 \mathrm{~s}$ at $80{ }^{\circ} \mathrm{C}$ followed by rinsing with copious amounts of deionized water. The glass was then cleaned for $2 \mathrm{~min}$ in $\mathrm{O}_{2}$ plasma (Harrick Plasma). Cleaned coverslips were placed under vacuum for long-term storage. Details of the passivation of the surface for correlation spectroscopy experiments and single protein binding experiments can be found in the caption of Figure S5.

Luminescence Correlation Spectroscopy. Luminescence of MUTAB-AuNRs was recorded with a home-built confocal microscope described elsewhere. ${ }^{72}$ The instrument is based on an inverted epifluorescence microscope (Observer.D1, Zeiss) equipped with a 638 nm diode laser (CUBE, Coherent). The laser light was collimated and delivered to the back aperture of an oil immersion objective (Apochromat 64×, NA = 1.4, Zeiss). The objective focused the light onto a small liquid cell placed on top of a glass coverslip containing 45 $\mu \mathrm{L}$ of sample solution. The emitted light was collected by the same objective and passed through a dichroic mirror (ZT 532/638 rpc, Chroma Technology), a long pass filter (XLP-647, CVI Melles-Griot), and a $50 \mu \mathrm{m}$ diameter pinhole (Thorlabs) placed at the focal plane of the microscope. The luminescence signal was detected by a single element diode detector (PDM 50ct, Micro-Photon-Devices) and processed by a home-built photon counting module (LabView). All measurements were recorded at a controlled laboratory temperature of $20 \pm 1{ }^{\circ} \mathrm{C}$, and using an excitation power of $1.5 \times 10^{3} \mathrm{~mW} / \mathrm{cm}^{2}$ at the sample. This excitation power ensured minimal heating and negligible autofluorescence background of unlabeled BSA (Figure S20). For protein concentration dependent measurements as summarized in
Table S1, 75 pM MUTAB-AuNR solutions with varying concentrations of BSA (Catalog \#A7906, Sigma-Aldrich; BSA concentrations, $0.1,0.5,1,1.5,2,3,4,5,10 \mathrm{nM}$; BSA/AuNR ratios, $1.33,6.66,13.33,20,26.66,40,53.33,66.66,133.33$ ) were prepared by mixing equal volumes of both solutions in buffer. The dimensions of the observation volume were determined using a calibration sample with a known diffusion coefficient at $20{ }^{\circ} \mathrm{C}$ (Figure S21).

Data Acquisition and Analysis for Correlation Spectroscopy Experiments. The luminescence intensity was recorded in data sets of $40 \mathrm{~s}$ at a temporal resolution of $10 \mu \mathrm{s}$. Each data set was autocorrelated using an automated routine in Matlab. At least seven data sets were averaged per measurement and the experiment was repeated independently three times at each protein concentration. The autocorrelation functions $G(\tau)$ were analyzed in Matlab using a one species, three-dimensional diffusion model with an additional exponential term that accounts for nanorod rotation: ${ }^{73}$

$$
G(\tau)=\frac{1}{\langle N\rangle}\left(1+\frac{\tau}{\tau_{\mathrm{D}}}\right)^{-1}\left(1+\left(\frac{r_{0}}{z_{0}}\right)^{2} \frac{\tau}{\tau_{\mathrm{D}}}\right)^{-(1 / 2)}\left(1+A \mathrm{e}^{-\left(\tau / \tau_{\mathrm{R}}\right)}\right)
$$

where $\langle N\rangle$ denotes the average number of particles in the threedimensional Gaussian-shaped observation volume, with radial and axial dimensions $r_{0}$ and $z_{0}$, respectively. The translational diffusion time $\tau_{\mathrm{D}}$ is related to the translational diffusion coefficient of the particles, $D_{\mathrm{tr}}=$ $r_{0}^{2} /\left(4 \tau_{\mathrm{D}}\right)$. An additional exponential term of amplitude $A$ and rotational diffusion time $\tau_{\mathrm{R}}$ was used to account for nanorod rotational diffusion. The translational diffusion coefficient was used to estimate the equivalent hydrodynamic radius of the nanoparticles using the Stokes-Einstein relationship $R_{\mathrm{h}}=k T / 6 \pi \eta D_{\text {tr }}$. Changes in viscosity due to the presence of BSA were calculated using the intrinsic viscosity of this protein $\left(4.2 \mathrm{~cm}^{3} / \mathrm{g}\right)$ assuming a linear relationship in the range of concentrations used. Results of correlation spectroscopy experiments before and after BSA binding at different concentrations are shown in Table S1.

Superlocalization Single Molecule Microscopy. Samples containing single immobilized MUTAB-AuNRs (Figures 2 and 3) and MUTAB-AuNPs (Figure 2) were prepared by dropcasting $\sim 40 \mu \mathrm{L}$ of $\sim 12.5 \mathrm{pM}$ of nanoparticle solutions (1:6 dilution of the concentration used for luminescence correlation spectroscopy experiments) on microscope coverslips passivated with unlabeled BSA (see caption of Figure S5 for details on the passivation procedure). The droplet was then dried for $10 \mathrm{~min}$ at room temperature, and the coverslips were rinsed with $1 \mathrm{~mL}$ of Millipore $\mathrm{H}_{2} \mathrm{O}$ and gently dried with nitrogen gas. A home-built total internal reflection wide field microscope with $637 \mathrm{~nm}$ excitation (Coherent OBIS-FP $637 \mathrm{LX}$ ) as described elsewhere ${ }^{74}$ was used with a custom flow chamber $(1 \mathrm{~mm}$ height, elliptical opening of $12 \times 5 \mathrm{~mm}$; 43018C, Grace BioLabs) placed over the sample containing immobilized MUTAB-nanoparticles. A solution of $2 \mathrm{nM}$ Alexa647-labeled BSA (A34785, Molecular Probes, 3 dyes/protein) was flowed over the sample at 5 $\mu \mathrm{L} / \mathrm{min}$ using a Genie Plus flow system (Kent Scientific). This flow rate does not impart strong forces on protein-binding site interactions and results in effectively negligible net directed diffusion due to flow. ${ }^{75}$ The sample was allowed to equilibrate for $15 \mathrm{~min}$ with protein flow before measuring, ensuring that an excess of proteins is exposed to each nanoparticle $\left(2 \mathrm{nmol} \mathrm{BSA} / \mathrm{L} \times 5 \mu \mathrm{L} / \min \times 15 \min \times N_{\mathrm{A}}=9 \times\right.$ $10^{10}$ BSA molecules compared to $\sim 10$ particles $/ 5 \mu \mathrm{m}^{2}$ in Figure $\mathrm{S} 3 \times$ $60 \mathrm{~mm}^{2}$ area of sample $=12 \times 10^{5}$ particles $/$ sample $)$. Data was collected at an incident excitation intensity of $5 \mathrm{~mW} / \mathrm{cm}^{2}$, an integration time of $100 \mathrm{~ms}$, frame rate of $7.5 \mathrm{~Hz}$, and electron multiplying gain of 300 . Analysis was possible at the superlocalization level, as the fluorescent BSA can be selectively observed only when adsorbed to the interface, and was unobservable by motion blur when freely diffusing $\left(D \sim 60 \mu \mathrm{m}^{2} / \mathrm{s}\right)$. Increases in signal-to-noise ratio of each frame, identification of adsorbed BSA, and superlocalization analysis of the location by radial symmetry fitting was performed using MATLAB 2011b as described previously. ${ }^{57,68}$ Samples containing single immobilized MUTAB-Au nanowires (Figures 2, 5c, and S14) were prepared using the same drying procedure, but because the 
concentration was unknown, the solution was repeatedly diluted until single isolated nanowires were observed in the optical microscope.

Circular Dichroism (CD) Spectroscopy. Ensemble CD measurements were taken on a J-815 circular dichroism spectrometer (JASCO) with a $1 \mathrm{~mm}$ path length quartz cuvette at $20 \pm 0.1{ }^{\circ} \mathrm{C}$ using a Peltier temperature controller. Equal volumes of $\sim 1 \mathrm{nM}$ nanoparticle solutions (MUTAB-AuNRs or AuNPs) and $0.1 \mathrm{mg} / \mathrm{mL}$ BSA solutions were mixed $\sim 30 \mathrm{~min}$ before each measurement. Wavelength ranges of $190-260$ and $500-750 \mathrm{~nm}$ were collected every $1 \mathrm{~nm}$ under standard sensitivity, bandwidth of $1.00 \mathrm{~nm}$, and rate of 50 $\mathrm{nm} / \mathrm{min}$. Four scans were collected for each trial and averaged. The spectra were baseline-corrected and presented as mean residue ellipticity. The solvent for CD measurements was $1 \mathrm{mM}$ phosphate buffer ( $\mathrm{pH}$ 7.2) due to its low absorbance in the far UV. This solvent did not affect the stability of MUTAB-AuNRs, MUTAB-AuNPs or BSA.

SEM Imaging. SEM images were taken using a FEI Quanta 400 ESEM FEG, operated at $10 \mathrm{kV}$ under low vacuum conditions. Analysis of aggregate size was performed in ImageJ.

MUTAB-AuNR Uptake by MCF-7 Cells. Preincubation of MUTAB-AuNRs under Different Media Conditions before Incubation with MCF-7 Cells. For the experiments shown in Figure 1a,b, MUTAB-AuNRs were incubated in two different media conditions: (1) $1 \mathrm{~mL}$ of MUTAB-AuNRs was mixed with $133 \mu \mathrm{L}$ of $7.5 \%(\mathrm{w} / \mathrm{v})$ BSA (final concentration of BSA $\sim 1 \% \mathrm{w} / \mathrm{v}$ ) and incubated overnight. This formed a BSA-corona onto the MUTAB-AuNRs before exposure to serum. Next, the BSA-MUTAB-AuNRs were diluted (1:10) in EMEM with 10\% FBS (with $1 \%$ PCN) and incubated overnight. (2) Then, $1 \mathrm{~mL}$ of MUTAB-AuNRs was directly diluted (1:10) in EMEM with 10\% FBS (with $1 \%$ PCN) and incubated overnight. Both MUTAB-AuNR solutions were found to be stable in EMEM over the time scale of the experiments, as observed via $\mathrm{UV} / \mathrm{vis}$ spectroscopy.

Nanoparticle Incubation with MCF-7 Cells. MCF-7 cells were seeded into two 6-well plates with each well containing $2 \mathrm{~mL}$ of 100000 cells $/ \mathrm{ml}$ solution and cultured for 3 days in EMEM with $10 \%$ FBS and 1\% PCN (same as incubation conditions for MUTABAuNRs). On the third day, the media was removed and each well was carefully washed three times with PBS to remove adhered proteins. Two wells were filled with $2 \mathrm{~mL}$ media containing either 1\% BSA, 10\% FBS in EMEM with $1 \%$ PCN, or 10\% FBS in EMEM with $1 \%$ PCN. The remainder of the wells contained $2 \mathrm{~mL}$ of the corresponding BSAMUTAB-AuNR solutions, each in triplicate. The plates were incubated at $37{ }^{\circ} \mathrm{C}$ in $4.5 \% \mathrm{CO}_{2}$ for $6 \mathrm{~h}$. After incubation for $6 \mathrm{~h}, 50 \mu \mathrm{L}$ of media from each well was removed in triplicate using a pipet and kept for the $\mathrm{LDH}$ assay. The wells were washed with PBS three times to remove adhered proteins and AuNRs. The cells were then detached via incubation in $0.05 \%$ trypsin with EDTA and counted using a standard hemacytometer (Figure S22). After counting, the cells were transferred to a solution of $0.1 \%$ Triton $\mathrm{X}-100$ and placed in a $-20{ }^{\circ} \mathrm{C}$ freezer overnight.

LDH Cytotoxicity Assay of MCF-7 Cells Incubated with BSAMUTAB-AuNRs. A LDH assay was performed by adding $50 \mu \mathrm{L}$ of formazan dye (Thermo Scientific) to each well containing media from the nanoparticle-cell incubation experiments (Figure S23). The plates were placed in an incubator at $37{ }^{\circ} \mathrm{C}$ with $4.5 \% \mathrm{CO}_{2}$ for $30 \mathrm{~min}$ and read on a BioTek Uniread 800 plate reader. The purpose of this assay was to measure the cytotoxicity of the MUTAB-AuNRs under the different incubation conditions with BSA and FBS, compared to MCF7 cells alone.

ICP-MS Measurement of BSA-MUTAB-AuNRs Uptaken by MCF-7 Cells. The lysed cells were thawed and centrifuged at $8000 \mathrm{~g}$ for $10 \mathrm{~min}$. The supernatant was removed and the pellets were digested using aqua regia (3:1 solution of $\mathrm{HNO}_{3}$ and $\mathrm{HCl}$ ). Following digestion, the pellets were diluted to $10 \mathrm{~mL}$ using $5 \% \mathrm{HCl}$ in milli-Q water. The samples were measured for Au concentration using a PerkinElmer Nexion 300 ICP-MS. The concentration of Au was determined for each cell using the cell count collected after detaching the cells (Figure S24).
Calculation of the Number of AuNRs Uptaken by Each Cell. The average number of AuNRs uptaken per cell was calculated by first determining the number of AuNRs in the different solutions with cells from the concentration of Au determined via ICP-MS. The number of AuNRs was then divided by the average number of cells. The addition of BSA to the MUTAB-AuNRs increases the uptake by MCF-7 cells by $320 \%$ compared to the conventional incubation conditions in EMEM with $10 \%$ FBS.

\section{ASSOCIATED CONTENT}

\section{Supporting Information}

The Supporting Information is available free of charge on the ACS Publications website at DOI: 10.1021/acsnano.5b06439.

Details regarding experimental and computational methods and data analysis (PDF)

Videos S1 and S2 (ZIP)

\section{AUTHOR INFORMATION}

\section{Corresponding Authors}

*E-mail: cflandes@rice.edu.

*E-mail: slink@rice.edu.

\section{Present Addresses}

${ }^{\#}$ CEA-Grenoble, 17 Rue des Martyrs, F-38054 Grenoble Cedex 9, France.

${ }^{\Delta}$ University of Illinois at Urbana-Champaign, School of Chemical Sciences, 600 S. Mathews Ave., MC-712, Box C-3, Urbana, IL 61801.

\section{Author Contributions}

${ }^{\| S}$. Dominguez-Medina and L. Kisley contributed equally to this work.

\section{Notes}

The authors declare no competing financial interest.

\section{ACKNOWLEDGMENTS}

This work was funded by the National Science Foundation (Grant CHE-1151647 to C. Landes; Grant CBET-1438634 to S. Link and C. Landes; Grant DMR-1105878 to E. Zubarev), the Welch Foundation (Grants C-1787 to C. Landes and C1664 to S. Link), and the American Chemical Society Petroleum Research Fund (54684-ND5 to C. Landes). L. Kisley and A. Hoggard acknowledge the National Science Foundation Graduate Research Fellowship (Grant 0940902). S. Dominguez-Medina acknowledges partial support from the Lodieska Stockbridge Vaughn Fellowship from Rice University. We would like to thank Professors Peter Wolynes, Naomi Halas, and Carsten Sönnichsen for their valuable feedback.

\section{REFERENCES}

(1) Xia, X.-R.; Monteiro-Riviere, N. A.; Riviere, J. E. An Index for Characterization of Nanomaterials in Biological Systems. Nat. Nanotechnol. 2010, 5, 671-675.

(2) Nel, A. E.; Mädler, L.; Velegol, D.; Xia, T.; Hoek, E. M. V; Somasundaran, P.; Klaessig, F.; Castranova, V.; Thompson, M. Understanding Biophysicochemical Interactions at the Nano-Bio Interface. Nat. Mater. 2009, 8, 543-557.

(3) Moyano, D. F.; Rotello, V. M. Nano Meets Biology: Structure and Function at the Nanoparticle Interface. Langmuir 2011, 27, 10376-10385.

(4) Pissuwan, D.; Valenzuela, S. M.; Cortie, M. B. Therapeutic Possibilities of Plasmonically Heated Gold Nanoparticles. Trends Biotechnol. 2006, 24, 62-67.

(5) Zharov, V. P.; Mercer, K. E.; Galitovskaya, E. N.; Smeltzer, M. S. Photothermal Nanotherapeutics and Nanodiagnostics for Selective 
Killing of Bacteria Targeted with Gold Nanoparticles. Biophys. J. 2006, 90, 619-627.

(6) Gobin, A. M.; Watkins, E. M.; Quevedo, E.; Colvin, V. L.; West, J. L. Near-Infrared-Resonant Gold/Gold Sulfide Nanoparticles as a Photothermal Cancer Therapeutic Agent. Small 2010, 6, 745-752.

(7) Nel, A.; Xia, T.; Mädler, L.; Li, N. Toxic Potential of Materials at the Nanolevel. Science 2006, 311, 622-627.

(8) Alkilany, A. M.; Nagaria, P. K.; Hexel, C. R.; Shaw, T. J.; Murphy, C. J.; Wyatt, M. D. Cellular Uptake and Cytotoxicity of Gold Nanorods: Molecular Origin of Cytotoxicity and Surface Effects. Small 2009, 5, 701-708.

(9) Dutta, D.; Sundaram, S. K.; Teeguarden, J. G.; Riley, B. J.; Fifield, L. S.; Jacobs, J. M.; Addleman, S. R.; Kaysen, G. A.; Moudgil, B. M.; Weber, T. J. Adsorbed Proteins Influence the Biological Activity and Molecular Targeting of Nanomaterials. Toxicol. Sci. 2007, 100, 303315.

(10) Colvin, V. L. The Potential Environmental Impact of Engineered Nanomaterials. Nat. Biotechnol. 2003, 21, 1166-1170.

(11) Kim, J. A.; Salvati, A.; Åberg, C.; Dawson, K. A. Suppression of Nanoparticle Cytotoxicity Approaching in Vivo Serum Concentrations: Limitations of in Vitro Testing for Nanosafety. Nanoscale 2014, 6, 14180-14184.

(12) Casals, E.; Pfaller, T.; Duschl, A.; Oostingh, G. J.; Puntes, V. Time Evolution of the Nanoparticle Protein Corona. ACS Nano 2010, 4, 3623-3632.

(13) Dobrovolskaia, M. A.; Patri, A. K.; Zheng, J.; Clogston, J. D.; Ayub, N.; Aggarwal, P.; Neun, B. W.; Hall, J. B.; McNeil, S. E. Interaction of Colloidal Gold Nanoparticles with Human Blood: Effects on Particle Size and Analysis of Plasma Protein Binding Profiles. Nanomedicine 2009, 5, 106-117.

(14) Lacerda, S. H. D. P.; Park, J. J.; Meuse, C.; Pristinski, D.; Becker, M. L.; Karim, A.; Douglas, J. F. Interaction of Gold Nanoparticles with Common Human Blood Proteins. ACS Nano 2010, 4, 365-379.

(15) Röcker, C.; Pötzl, M.; Zhang, F.; Parak, W. J.; Nienhaus, G. U. A Quantitative Fluorescence Study of Protein Monolayer Formation on Colloidal Nanoparticles. Nat. Nanotechnol. 2009, 4, 577-580.

(16) Tenzer, S.; Docter, D.; Rosfa, S.; Wlodarski, A.; Kuharev, J.; Rekik, A.; Knauer, S. K.; Bantz, C.; Nawroth, T.; Bier, C.; Sirirattanapan, J.; Mann, W.; Treuel, L.; Zellner, R.; Maskos, M.; Schild, H.; Stauber, R. H. Nanoparticle Size Is a Critical Physicochemical Determinant of the Human Blood Plasma Corona: A Comprehensive Quantitative Proteomic Analysis. ACS Nano 2011, 5, 7155-7167.

(17) Brewer, S. H.; Glomm, W. R.; Johnson, M. C.; Knag, M. K.; Franzen, S. Probing BSA Binding to Citrate-Coated Gold Nanoparticles and Surfaces. Langmuir 2005, 21, 9303-9307.

(18) Mahmoudi, M.; Lynch, I.; Ejtehadi, M. R.; Monopoli, M. P.; Bombelli, F. B.; Laurent, S. Protein-Nanoparticle Interactions: Opportunities and Challenges. Chem. Rev. 2011, 111, 5610-5637.

(19) Walkey, C. D.; Chan, W. C. W. Understanding and Controlling the Interaction of Nanomaterials with Proteins in a Physiological Environment. Chem. Soc. Rev. 2012, 41, 2780-2799.

(20) Monopoli, M. P.; Walczyk, D.; Campbell, A.; Elia, G.; Lynch, I.; Bombelli, F. B.; Dawson, K. A. Physical-Chemical Aspects of Protein Corona: Relevance to in Vitro and in Vivo Biological Impacts of Nanoparticles. J. Am. Chem. Soc. 2011, 133, 2525-2534.

(21) Ritz, S.; Schöttler, S.; Kotman, N.; Baier, G.; Musyanovych, A.; Kuharev, J.; Landfester, K.; Schild, H.; Jahn, O.; Tenzer, S.; Mailänder, V. Protein Corona of Nanoparticles: Distinct Proteins Regulate the Cellular Uptake. Biomacromolecules 2015, 16, 1311-1321.

(22) Sisco, P. N.; Wilson, C. G.; Chernak, D.; Clark, J. C.; Grzincic, E. M.; Ako-Asare, K.; Goldsmith, E. C.; Murphy, C. J. Adsorption of Cellular Proteins to Polyelectrolyte-Functionalized Gold Nanorods: A Mechanism for Nanoparticle Regulation of Cell Phenotype? PLoS One 2014, 9, e86670.

(23) Pino, P. del; Pelaz, B.; Zhang, Q.; Maffre, P.; Nienhaus, G. U.; Parak, W. J. Protein Corona Formation around Nanoparticles - from the Past to the Future. Mater. Horiz. 2014, 1, 301-313.
(24) Treuel, L.; Docter, D.; Maskos, M.; Stauber, R. H. Protein Corona - from Molecular Adsorption to Physiological Complexity. Beilstein J. Nanotechnol. 2015, 6, 857-873.

(25) Winuprasith, T.; Chantarak, S.; Suphantharika, M.; He, L.; McClements, D. J. Alterations in Nanoparticle Protein Corona by Biological Surfactants: Impact of Bile Salts on B-Lactoglobulin-Coated Gold Nanoparticles. J. Colloid Interface Sci. 2014, 426, 333-340.

(26) Landgraf, L.; Christner, C.; Storck, W.; Schick, I.; Krumbein, I.; Dähring, H.; Haedicke, K.; Heinz-Herrmann, K.; Teichgräber, U.; Reichenbach, J. R.; Tremel, W.; Tenzer, S.; Hilger, I. A Plasma Protein Corona Enhances the Biocompatibility of Au@Fe3O4 Janus Particles. Biomaterials 2015, 68, 77-88.

(27) Darabi Sahneh, F.; Scoglio, C.; Riviere, J. Dynamics of Nanoparticle-Protein Corona Complex Formation: Analytical Results from Population Balance Equations. PLoS One 2013, 8, e64690.

(28) Deng, Z. J.; Liang, M.; Monteiro, M.; Toth, I.; Minchin, R. F. Nanoparticle-Induced Unfolding of Fibrinogen Promotes Mac-1 Receptor Activation and Inflammation. Nat. Nanotechnol. 2011, 6, 39-44.

(29) Monopoli, M. P.; Aberg, C.; Salvati, A.; Dawson, K. A. Biomolecular Coronas Provide the Biological Identity of Nanosized Materials. Nat. Nanotechnol. 2012, 7, 779-786.

(30) Tenzer, S.; Docter, D.; Kuharev, J.; Musyanovych, A.; Fetz, V.; Hecht, R.; Schlenk, F.; Fischer, D.; Kiouptsi, K.; Reinhardt, C.; Landfester, K.; Schild, H.; Maskos, M.; Knauer, S. K.; Stauber, R. H. Rapid Formation of Plasma Protein Corona Critically Affects Nanoparticle Pathophysiology. Nat. Nanotechnol. 2013, 8, 772-781.

(31) Cedervall, T.; Lynch, I.; Lindman, S.; Berggård, T.; Thulin, E.; Nilsson, H.; Dawson, K. A.; Linse, S. Understanding the NanoparticleProtein Corona Using Methods to Quantify Exchange Rates and Affinities of Proteins for Nanoparticles. Proc. Natl. Acad. Sci. U. S. A. 2007, 104, 2050-2055.

(32) Lundqvist, M.; Stigler, J.; Elia, G.; Lynch, I.; Cedervall, T.; Dawson, K. A. Nanoparticle Size and Surface Properties Determine the Protein Corona with Possible Implications for Biological Impacts. Proc. Natl. Acad. Sci. U. S. A. 2008, 105, 14265-14270.

(33) Walkey, C. D.; Olsen, J. B.; Guo, H.; Emili, A.; Chan, W. C. W. Nanoparticle Size and Surface Chemistry Determine Serum Protein Adsorption and Macrophage Uptake. J. Am. Chem. Soc. 2012, 134, 2139-2147.

(34) Mahmoudi, M.; Lohse, S. E.; Murphy, C. J.; Fathizadeh, A.; Montazeri, A.; Suslick, K. S. Variation of Protein Corona Composition of Gold Nanoparticles Following Plasmonic Heating. Nano Lett. 2014, $14,6-12$.

(35) Dominguez-Medina, S.; McDonough, S.; Swanglap, P.; Landes, C. F.; Link, S. In Situ Measurement of Bovine Serum Albumin Interaction with Gold Nanospheres. Langmuir 2012, 28, 9131-9139.

(36) Nienhaus, G. U.; Maffre, P.; Nienhaus, K. Studying the Protein Corona on Nanoparticles by FCS. Methods Enzymol. 2013, 519, 115137.

(37) Ament, I.; Prasad, J.; Henkel, A.; Schmachtel, S.; Sönnichsen, C. Single Unlabeled Protein Detection on Individual Plasmonic Nanoparticles. Nano Lett. 2012, 12, 1092-1095.

(38) Zijlstra, P.; Paulo, P. M. R.; Orrit, M. Optical Detection of Single Non-Absorbing Molecules Using the Surface Plasmon Resonance of a Gold Nanorod. Nat. Nanotechnol. 2012, 7, 379-382.

(39) Dominguez-Medina, S.; Blankenburg, J.; Olson, J.; Landes, C. F.; Link, S. Adsorption of a Protein Monolayer via Hydrophobic Interactions Prevents Nanoparticle Aggregation under Harsh Environmental Conditions. ACS Sustainable Chem. Eng. 2013, 1, 833-842.

(40) Doorley, G. W.; Payne, C. K. Cellular Binding of Nanoparticles in the Presence of Serum Proteins. Chem. Commun. 2011, 47, 466468.

(41) Doorley, G. W.; Payne, C. K. Nanoparticles Act as Protein Carriers during Cellular Internalization. Chem. Commun. 2012, 48, 2961-2963.

(42) Deng, Z. J.; Liang, M.; Toth, I.; Monteiro, M. J.; Minchin, R. F. Molecular Interaction of Poly(acrylic Acid) Gold Nanoparticles with Human Fibrinogen. ACS Nano 2012, 6, 8962-8969. 
(43) Chakraborty, S.; Joshi, P.; Shanker, V.; Ansari, Z. A.; Singh, S. P.; Chakrabarti, P. Contrasting Effect of Gold Nanoparticles and Nanorods with Different Surface Modifications on the Structure and Activity of Bovine Serum Albumin. Langmuir 2011, 27, 7722-7731.

(44) Zhang, D.; Neumann, O.; Wang, H.; Yuwono, V. M.; Barhoumi, A.; Perham, M.; Hartgerink, J. D.; Wittung-Stafshede, P.; Halas, N. J. Gold Nanoparticles Can Induce the Formation of Protein-Based Aggregates at Physiological pH. Nano Lett. 2009, 9, 666-671.

(45) Pan, H.; Qin, M.; Meng, W.; Cao, Y.; Wang, W. How Do Proteins Unfold upon Adsorption on Nanoparticle Surfaces? Langmuir 2012, 28, 12779-12787.

(46) Medintz, I. L.; Konnert, J. H.; Clapp, A. R.; Stanish, I.; Twigg, M. E.; Mattoussi, H.; Mauro, J. M.; Deschamps, J. R. A Fluorescence Resonance Energy Transfer-Derived Structure of a Quantum DotProtein Bioconjugate Nanoassembly. Proc. Natl. Acad. Sci. U. S. A. 2004, 101, 9612-9617.

(47) Roach, P.; Farrar, D.; Perry, C. C. Interpretation of Protein Adsorption: Surface-Induced Conformational Changes. J. Am. Chem. Soc. 2005, 127, 8168-8173.

(48) Wangoo, N.; Suri, C. R.; Shekhawat, G. Interaction of Gold Nanoparticles with Protein: A Spectroscopic Study to Monitor Protein Conformational Changes. Appl. Phys. Lett. 2008, 92, 133104.

(49) Fleischer, C. C.; Payne, C. K. Nanoparticle-Cell Interactions: Molecular Structure of the Protein Corona and Cellular Outcomes. Acc. Chem. Res. 2014, 47, 2651-2659.

(50) Chakraborti, S.; Joshi, P.; Chakravarty, D.; Shanker, V.; Ansari, Z. A.; Singh, S. P.; Chakrabarti, P. Interaction of PolyethyleneimineFunctionalized $\mathrm{ZnO}$ Nanoparticles with Bovine Serum Albumin. Langmuir 2012, 28, 11142-11152.

(51) Cedervall, T.; Lynch, I.; Foy, M.; Berggård, T.; Donnelly, S. C.; Cagney, G.; Linse, S.; Dawson, K. A. Detailed Identification of Plasma Proteins Adsorbed on Copolymer Nanoparticles. Angew. Chem., Int. Ed. 2007, 46, 5754-5756.

(52) Vigderman, L.; Manna, P.; Zubarev, E. R. Quantitative Replacement of Cetyl Trimethylammonium Bromide by Cationic Thiol Ligands on the Surface of Gold Nanorods and Their Extremely Large Uptake by Cancer Cells. Angew. Chem. 2012, 124, 660-665.

(53) Peters, T. All about Albumin; Elsevier, 1995.

(54) Treuel, L.; Brandholt, S.; Maffre, P.; Wiegele, S.; Shang, L.; Nienhaus, G. U. Impact of Protein Modification on the Protein Corona on Nanoparticles and Nanoparticle-Cell Interactions. ACS Nano 2014, 8, 503-513.

(55) Pelaz, B.; del Pino, P.; Maffre, P.; Hartmann, R.; Gallego, M.; Rivera-Fernández, S.; de la Fuente, J. M.; Nienhaus, G. U.; Parak, W. J. Surface Functionalization of Nanoparticles with Polyethylene Glycol: Effects on Protein Adsorption and Cellular Uptake. ACS Nano 2015, 9, 6996-7008.

(56) Chen, J.; Bremauntz, A.; Kisley, L.; Shuang, B.; Landes, C. F. Super-Resolution mbPAINT for Optical Localization of SingleStranded DNA. ACS Appl. Mater. Interfaces 2013, 5, 9338-9343.

(57) Shuang, B.; Chen, J.; Kisley, L.; Landes, C. F. Troika of Single Particle Tracking Programing: SNR Enhancement, Particle Identification, and Mapping. Phys. Chem. Chem. Phys. 2014, 16, 624-634.

(58) Das, S. K.; Darshi, M.; Cheley, S.; Wallace, M. I.; Bayley, H. Membrane Protein Stoichiometry Determined from the Step-Wise Photobleaching of Dye-Labelled Subunits. ChemBioChem 2007, 8, 994-999.

(59) Ding, H.; Wong, P. T.; Lee, E. L.; Gafni, A.; Steel, D. G. Determination of the Oligomer Size of Amyloidogenic Protein Betaamyloid(1-40) by Single-Molecule Spectroscopy. Biophys. J. 2009, 97, 912-921.

(60) Kastantin, M.; Langdon, B. B.; Chang, E. L.; Schwartz, D. K. Single-Molecule Resolution of Interfacial Fibrinogen Behavior: Effects of Oligomer Populations and Surface Chemistry. J. Am. Chem. Soc. 2011, 133, 4975-4983.

(61) Casanova, D.; Giaume, D.; Moreau, M.; Martin, J.-L.; Gacoin, T.; Boilot, J.-P.; Alexandrou, A. Counting the Number of Proteins Coupled to Single Nanoparticles. J. Am. Chem. Soc. 2007, 129, 1259212593.
(62) Whitmore, L.; Wallace, B. A. DICHROWEB, an Online Server for Protein Secondary Structure Analyses from Circular Dichroism Spectroscopic Data. Nucleic Acids Res. 2004, 32, W668-W673.

(63) Andrade, M. A.; Chacón, P.; Merelo, J. J.; Morán, F. Evaluation of Secondary Structure of Proteins from UV Circular Dichroism Spectra Using an Unsupervised Learning Neural Network. Protein Eng., Des. Sel. 1993, 6, 383-390.

(64) George, J.; Thomas, K. G. Surface Plasmon Coupled Circular Dichroism of Au Nanoparticles on Peptide Nanotubes. J. Am. Chem. Soc. 2010, 132, 2502-2503.

(65) Lu, F.; Tian, Y.; Liu, M.; Su, D.; Zhang, H.; Govorov, A. O.; Gang, O. Discrete Nanocubes as Plasmonic Reporters of Molecular Chirality. Nano Lett. 2013, 13, 3145-3151.

(66) Wang, R.-Y.; Wang, P.; Liu, Y.; Zhao, W.; Zhai, D.; Hong, X.; Ji, Y.; Wu, X.; Wang, F.; Zhang, D.; Zhang, W.; Liu, R.; Zhang, X. Experimental Observation of Giant Chiroptical Amplification of Small Chiral Molecules by Gold Nanosphere Clusters. J. Phys. Chem. C 2014, $118,9690-9695$.

(67) Govorov, A. O.; Fan, Z.; Hernandez, P.; Slocik, J. M.; Naik, R. R. Theory of Circular Dichroism of Nanomaterials Comprising Chiral Molecules and Nanocrystals: Plasmon Enhancement, Dipole Interactions, and Dielectric Effects. Nano Lett. 2010, 10, 1374-1382.

(68) Parthasarathy, R. Rapid, Accurate Particle Tracking by Calculation of Radial Symmetry Centers. Nat. Methods 2012, 9, 724-726.

(69) Su, L.; Lu, G.; Kenens, B.; Rocha, S.; Fron, E.; Yuan, H.; Chen, C.; Van Dorpe, P.; Roeffaers, M. B. J.; Mizuno, H.; Hofkens, J.; Huchison, J. A.; Uji-i, H. Visualization of Molecular Fluorescence Point Spread Functions via Remote Excitation Switching Fluorescence Microscopy. Nat. Commun. 2015, 6, 6287.

(70) Cukalevski, R.; Ferreira, S.; Dunning, C. IgG and Fibrinogen Driven Nanoparticle Aggregation. Nano Res. 2015, 8, 2733.

(71) Khanal, B. P.; Zubarev, E. R. Purification of High Aspect Ratio Gold Nanorods: Complete Removal of Platelets. J. Am. Chem. Soc. 2008, 130, 12634-12635.

(72) Tcherniak, A.; Dominguez-Medina, S.; Chang, W.-S.; Swanglap, P.; Slaughter, L. S.; Landes, C. F.; Link, S. One-Photon Plasmon Luminescence and Its Application to Correlation Spectroscopy as a Probe for Rotational and Translational Dynamics of Gold Nanorods. J. Phys. Chem. C 2011, 115, 15938-15949.

(73) Tirado, M. M.; Martínez, C. L.; de la Torre, J. G. Comparison of Theories for the Translational and Rotational Diffusion Coefficients of Rod-like Macromolecules. Application to Short DNA Fragments. J. Chem. Phys. 1984, 81, 2047.

(74) Kisley, L.; Chang, W.-S.; Cooper, D.; Mansur, A. P.; Landes, C. F. Extending Single Molecule Fluorescence Observation Time by Amplitude-Modulated Excitation. Methods Appl. Fluoresc. 2013, 1, 037001.

(75) Kisley, L.; Chen, J.; Mansur, A. P.; Shuang, B.; Kourentzi, K.; Poongavanam, M.-V.; Chen, W.-H.; Dhamane, S.; Willson, R. C.; Landes, C. F. Unified Superresolution Experiments and Stochastic Theory Provide Mechanistic Insight into Protein Ion-Exchange Adsorptive Separations. Proc. Natl. Acad. Sci. U. S. A. 2014, 111, 2075-2080. 